Journal of Information Systems Engineering

\& Management, 2018, 3(3), 20

ISSN: 2468-4376

\title{
Evaluation of the Effects of SaaS on SMEs in Nairobi County, Kenya
}

\author{
Paul Mwaniki ${ }^{1 *}$, Collins Oduor Ondiek ${ }^{2}$ \\ ${ }^{1}$ Instructor, School of Computing Sciences, Riara University, Nairobi, KENYA \\ ${ }^{2}$ Lecturer, Department of Computer Science, Africa Nazarene University, Nairobi, KENYA
}

*Corresponding Author: pmwaniki@riarauniversity.ac.ke

Citation: Mwaniki, P. and Ondiek, C. O. (2018). Evaluation of the Effects of SaaS on SMEs in Nairobi

County, Kenya. Journal of Information Systems Engineering \& Management, 3(3), 20. https://doi.org/10.20897/jisem/2656

Published: July 16, 2018

\begin{abstract}
SMEs in Kenya form the majority of enterprises in Kenya providing close to $80 \%$ of Kenya's employment. Although they are the majority they perform dismally contributing very poorly to the country's Gross Domestic Product (GDP). GDP is the monetary value of all the finished goods and services produced within a country's borders in a specific time period. Past statistics indicate that three out of five businesses fail within the first few months of operation and those that continue, 80 per cent fail before the fifth year. This means that there is a sustainability issue among small to medium-sized enterprises (SMEs). If SMEs adopted information and communications technology (ICT) solutions their sustainability would increase, but the main challenge SMEs face with implementing ICT solutions is the high cost of implementation and maintenance. The purpose of this research was to evaluate the effects of SaaS on SMEs in Nairobi County, Kenya to find out if SaaS was affordable and if it improved the SMEs. The effects that were evaluated were end user effects, economic effects and functional effects. Literature review of SMEs, SaaS and the effect that SaaS has on SMEs in various countries was done. The study which followed the explanatory research design evaluated 35 SMEs in Nairobi County, Kenya. This number was identified through a sample formulae. The data collected through a questionnaire was then analyzed and indicated that SaaS use had positive end user, economic and functional effects on SMEs. The study then recommended that SMEs in Nairobi County, Kenya, should be encouraged to use SaaS as it would improve their performance.
\end{abstract}

Keywords: SaaS, SMEs, end user effects, functional effects, economic effects

\section{INTRODUCTION}

Businesses and enterprises should take advantage of technological innovations by applying them in their daily routines and activities. This would improve their processes and also affirm their credibility. Peppard (1993) states that when enterprises adopt Information Technology (IT) they are able to improve their old processes through new technology thus making them faster and more efficient and also "radically changing the way business is conducted". This can greatly improve the performance of businesses and increase their efficiency and service delivery especially if there is an affordable way for implementing technology in their processes.

\section{Background of the Study}

There exists many different technologies that enterprises can apply and benefit from by applying them correctly in their various businesses processes. The different technologies provide enterprises with different solutions depending on the challenges they face, area of improvement or context they face. However, implementing and integrating IT (Information Technology) in enterprises has its challenges (Sanchita, 2013). The challenges include 
adoption to the technologies, change of culture at the work place, data and infrastructure insecurity, expensiveness of the infrastructure, adopting to the technology, training the employees which may take time and the implementation process of IT which includes customisation and integration (Sanchita, 2013). Some of this challenges are experienced more by Small and Medium Based Enterprises (SMEs) as they do not have a lot of resources. New technologies and innovations are being developed to address such challenges that the SMEs face (Peppard, 1993).

The introduction of the emerging technology Software as a Service (SaaS) may able to solve this challenges. It is a new technology that delivers software online as a service where the host of the software or the servers are remotely located away from the user (Wohl, 2008). The SaaS concept provides advantages such as faster implementation of software changes and reduces the hustle of installation of the software and hardware, control of the software and hardware and maintenance of the software and hardware, which can greatly assist the Small and Medium Based Enterprises. (SMEs) (Bennet, 2001).

This research aimed at studying the effects of SaaS on SMEs in terms of end user effects, functional effects and economic effects in order to find out if SaaS use actually improved SMEs performance.

\section{Problem of Research}

Past statistics show that $80 \%$ of the SMEs are unsuccessful before their third year and three out of five SMEs are unsuccessful during the initial months of running and the business (Kenya National Bureau of Statistics, 2007). This is a high failure rate amongst the SMEs taking into account the important role that SMEs play in fueling economic growth by creating employment opportunities, increasing the tax collection, and the role they hold in innovation (Ngui, 2014). There is need of solutions to improve the sustainability issue among SMEs. The SMEs can implement IT solutions to improve business processes but the main challenge is the high cost of implementation and maintenance of onsite IT solutions (Mpho, 2013). There is need of a cost effective way for SMEs to implement IT which still improves their performance leading to a higher rate of sustainability. A study of the effects of SaaS on SMEs can show if use of SaaS improves the SMEs.

\section{Objective of the Study}

The objective of this study was to identify the effects of SaaS on SMEs in Nairobi County, Kenya. The aim was to find out if SaaS as a solution if implemented by SMEs improved their performance and their sustainability. This was measured by evaluating the end user effects, functional effects and economic effects of SaaS use. The end user effects included the following key factors: Teleworking, reduction in number of IT staff, reduced training needs, ease of use and increased customer satisfaction. The functional effects included the following key factors: difficulty of deploying SaaS, competitiveness, dependability and SaaS ability to assist in solving business objectives. The economic effects included the following key factors: increase in revenue, reduce required upfront investments, reduce maintenance cost and increase in acquiring targeted customers.

\section{Scope of the study}

This research aimed at focusing on SMEs in Nairobi County, as these companies are able to access technology at a faster rate and easier way. This is because in Kenya, most Internet service providers (ISPs) are based in Nairobi and this enables enterprises based in Nairobi to access them with more ease.

\section{LITERATURE REVIEW}

\section{Theoretical Review of Literature}

This study followed the technology deterministic theory. Technological determinism theory aims at showing how technology and emerging technology i.e. media, or technology as a whole, as the key mover social change and history (Kunz, 2006). In this case, the study was to show how technical development and use of SaaS which is in an emerging technology has affected SMEs in terms of user effects, functional effects and economic effects.

\section{Small and Medium Based Enterprises}

Although they may be a general definition of SME the term is understood differently in different contexts. Garikai (2011) states that the definition of SMEs depends on the number of employees, the capital used and the amount of money they receive from their sales annually. But according to Ngui (2014) arrangement of SMEs by their size is relevant to the sector they are operating in. A business of a certain size could be considered to be small in relation to another industry where the market is large and there are a larger size of competitors: while an enterprise of the same size may be classified as large in another industry that has fewer enterprises or has smaller firms in that particular sector. 
Ngui (2014) further states that it is not right to classify and explain size by the number of people who have been employed but rather in some sectors it would be better to use the amount of money received annually. Generally in most governments, the norm is usually to measure size by examining the total numbers of people who have been employed on a full time basis (Ngui, 2014).The Government of Kenya has SMEs defined as a lawfully registered company that has the number of employed people to be between 1 to 150 employees and has annual income generated that is less than 100 million Kenyan Shillings (Moyi, 2005). This is the definition that was taken into consideration as SMEs were chosen for the aim of this research because it aimed on SMEs in Nairobi County which is in Kenya.

\section{Importance of SMEs}

Small enterprises in Kenya are defined, as those organizations where the employees number is between $9-49$, while the medium enterprises are defined as those organizations having an employee number of between 49-99 employees. The organizations where the employee number is less than 5 are known as micro enterprises (Migir 2006). The significance of Kenya's SMEs was identified in the International Labour Organization report (ILO) in 1972 on 'Employment, Income and Equity in Kenya' (ILO, 1972). The report outlined the SMEs as key drivers for income generation and job creation. According to the African Economic Outlook report (2011) SMEs create close to $80 \%$ of employment. This shows the significance of SMEs in Kenya.

According to Dr. Ngui Thomas (2014), SMEs role in development of the economy and creation of employment opportunities has been in most discussions among most of the academicians, policy makers and governments around the globe. He further notes that this SMEs are capable of fueling economic growth because they create employment opportunities, increase the tax collection, and play a critical role in innovation. They are also noted to be the most important business where the companies develop the economy with a consistent pool of skills, innovations and ideas (Ngui, 2014). This is due to the high level of competition among them in different areas that leads to the high supply of ideas skills and innovations. SMEs are also noted as high providers of employment and are accredited as good income generators that provide training opportunities and other significant basic services to people who are disadvantaged (Tilman, 2006). Around the world there is a general accordance that the SMEs play a critical role in economic development which is based on the rapid improvements of the businesses and the role of job generation that they hold (Ngui, 2014).

\section{SaaS}

Cloud computing is an emerging technology that has led to portable, efficient, on-demand network access to group of customizable information and communications technology (ICT) resources i.e. Network infrastructure, servers and storage resources, software etc. that can be quickly acquired, customized and adopted with very little interaction of the service provider (Wu, 2009). SaaS is a cloud computing model which offers a shared software service where the applications that are used by the subscribers/clients are hosted by the service provide and the clients can be able to access them through a network which is usually the internet (Satyanarayana, 2011). This ensures that the clients have no interest with maintaining the backend i.e. updates and patches, hardware maintenance etc. but are only focused on using and configuring the software.

\section{Effects of SaaS on SMEs}

SaaS affects SMEs in different ways. A study on the effects SaaS has on SMEs in Sweden was done and different conclusions were drawn (Mikael, 2015). The five SMEs that were studied reported that they experienced a reduced need for hardware investments due to scalability of the SaaS price model. The greatest effect mentioned about SaaS is that it is initially cheaper with only a low initial cost though they added that it might be more expensive in the long run. Effects of frequent updates was also noted from the research done in Sweden where bugs as a result of updates lead to work around solutions, bugs interfering with own program code lead to extra testing and reprogramming. The effects of the mobility nature of SaaS model on SMEs were also noted where not being restricted to a specific location when working in the system, possibility to let customers see product under development, increased ability to reach global markets, platform independence due to web browser access, being able to work while travelling (if there is Internet access), and possibly of increased stress due to increased ability to work from home were the main effects noted. The study concluded the issues that affected the SMEs that used SaaS could be summarized and revolved around: Availability and down-time, Data integrity, frequent updates, Integration, IT department, Lock-in, Mobility, Performance, Price model, Privacy and confidentiality, Standardization, Vendor relation and Usability (Mikael, 2015).

A research study in Nigeria on SMEs using SaaS showed that the SMEs were able to cost cut on expenses that were used to hire IT personnel for maintenance thus also reducing the maintenance cost (Abubakar, 2014). The study also revealed that SMEs there claimed it is cheaper and more efficient to use the cloud services. Lastly the SMEs stated there were solutions available on the cloud that they did not need to buy the enterprise license for all 
the time. In South Africa SMEs stated that the major effect of cloud computing on SMEs is cost savings because most SMEs perceive the normal ICT services to be expensive to adopt and maintain. They stated that Cloud computing allowed them to adopt cloud services which is affordable (Mpho, 2013).

\section{RESEARCH DESIGN AND METHODOLOGY}

\section{Research Design}

This can be stated to be an outline that is used to produce answers to the research issues (Kombo and Tromp, 2006). In this case the study adopted an explanatory research where SMEs that were using SaaS were studied in order to understand the effects of SMEs using SaaS.

\section{Research Site}

The research site for this study was Nairobi County. This is because of the availability and ease of use of internet connectivity as it is the capital city of Kenya and has more developed infrastructure than any other city in the country. This was assumed to lead more SMEs using SaaS than any other SMEs based in another city thus leading to the researcher having a bigger pool of SMEs to gather data from. It was also assumed since the use of SaaS which is an emerging technology, the use of it would be more in the capital city than the other cities as it was still a fairly new technology in the country.

\section{Target Population}

Target population is termed as the number of people to whom the research results are to apply to (Singh and Masaku, 2014). In our study the target population included all the SMEs that were in Nairobi County that were using SMEs. Once the study had been conducted then the SMEs would then have the ability to gauge if the effects of using SaaS were improving or decreasing their performance.

\section{Determination of Study Samples}

\section{Sampling Procedure}

The type of sampling technique used were purposive sampling and snowball sampling technique. Purposive sampling is where the researcher makes strategic decisions on with whom where and how they select the sample to make the sample representative (Palys, 2008). Snowball sampling is a technique for finding research subjects where one subject gives the researcher the name of another subject, who in turn provides the name of a third, and so on (Vogt, 1999). The identified SMEs that were using SaaS were asked by the researcher to assist in identifying SMEs that also use SaaS. This is where the snowball sampling technique was used. This method was used because of the SaaS provider's reluctance to provide information about its clients due to security reasons. This two methods of selecting the representative sample were chosen because of factors that the study aimed to achieve and also because of factors that were out of the researcher's control.

\section{Study Sample Size}

Sample size is termed to be a number of people from the study population from whom the data is collected (Singh and Masaku, 2014). The SMEs that were used in the study needed to have used SaaS for a period of two months minimum.

The sample size of this SMEs were determined using the Cochran's Sample Size Formula (Singh and Masaku, 2014):

where:

$$
n=\frac{\left(z^{2} * p * q\right)}{d^{2}}
$$

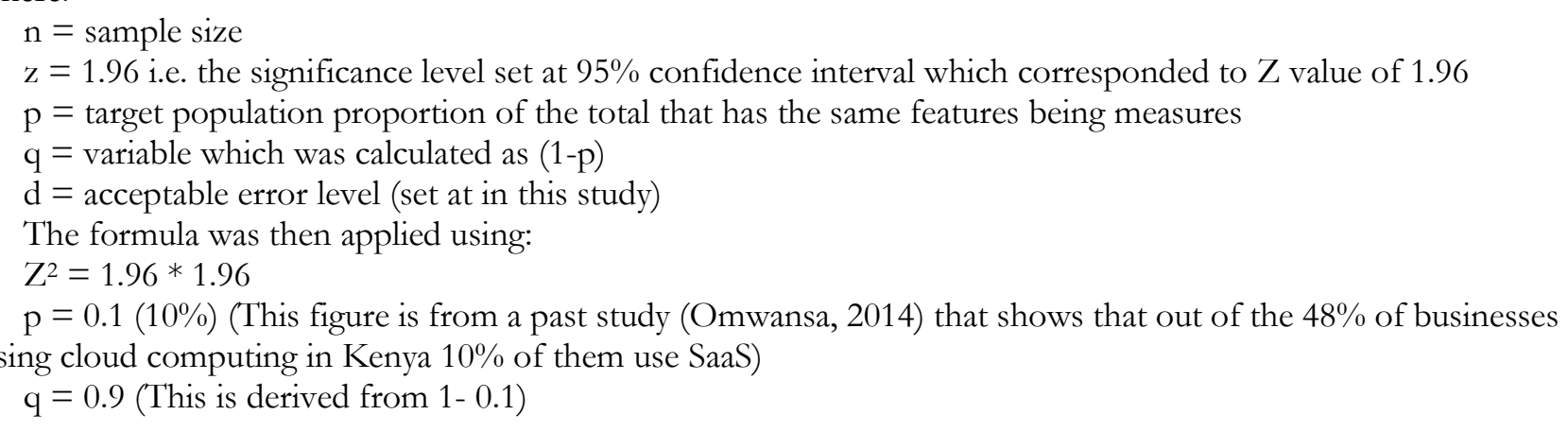


$\mathrm{d}=0.1$ (The acceptable error level is $10 \%$, this is a bit high because at the time of undertaking this study there was no official documentation of SMEs using SaaS)

The sample size required to collect data was thus determined to be: 35 SMEs

\section{Data Collection Measures}

\section{Development of Instruments}

The study included collection of data through quantitative data collection techniques, specifically questionnaires. Quantitative collection techniques are characterised by the gathering of data that can be analysed numerically, the results of which are usually presented using graphs, tables and figures (Given, 2008). The structured questionnaires were availed to the respondents in person.

\section{Pilot Testing of Research Instrument}

The questionnaire was pilot tested by issuing it to academic professionals in the field of cloud computing and four SMEs that were using SaaS. Afterwards the questionnaire was restructured considering the feedback from the academic professionals and the four SMEs.

\section{Instrument Validity}

Validity is termed to be the degree of an instrument measuring what it is supposed to measure (Carole, 2008).

\section{Translation Validity}

In this study translation validity was considered. This is where operationalization reflects the true meaning of the construct (Drost, 2011). This is where the population of interest in the study is the "construct", in our case SMEs using SaaS in Nairobi County, and the sample is the operationalization where in our case this is the thirty five SMEs that were selected. Translation validity was ensured by using a sample formula and documented numbers from previous studies done in the county. This is explained in section 3.5.

\section{Content Validity}

The questionnaire underwent content validity. This a type of validity in where; different skills, behaviours and elements are measured well (Mohammad, 2013). This led to the research instrument being reviewed by the experts in the area of research and then based on the reviewer's views the questions were changed so that they were clear enough and were up to standard. Here, the questionnaire was reviewed by experts in the cloud computing field from both the academic and business field before the questionnaires were distributed to the SMEs identified for the sample size.

\section{RESULTS AND ANALYSIS}

\section{End User Effects}

The respondents were asked to state the extent to which they agreed to the statements on end user effects as a result of adoption and use of SaaS. This was on a scale of 1-5, strongly disagree (1); disagree (2); neutral (3); agree (4); strongly agree (5). The key factors rated by the respondents were: Teleworking, reduction in number of IT staff, reduced training needs, ease of use and increased customer satisfaction. All the 35 respondents from the 35 SMEs filled the questionnaire appropriately. The findings are presented in Table 1.

Table 1. Respondents end user effects of using SaaS

\begin{tabular}{|c|c|c|c|c|c|c|}
\hline & $\begin{array}{l}\text { Strongly } \\
\text { Disagree }\end{array}$ & Disagree & Neutral & Agree & $\begin{array}{c}\text { Strongly } \\
\text { Agree }\end{array}$ & Total \\
\hline Use of SaaS enables me to work away from the office frequently & $0 \%$ & $0 \%$ & $8.3 \%$ & $27.8 \%$ & $63.9 \%$ & $100 \%$ \\
\hline SaaS has led to a reduced number of IT staff & $2.8 \%$ & $2.8 \%$ & $25 \%$ & $36.1 \%$ & $33.3 \%$ & $100 \%$ \\
\hline Use of SaaS does not need any training & $8.3 \%$ & $19.4 \%$ & $19.4 \%$ & $30.6 \%$ & $22.2 \%$ & $100 \%$ \\
\hline It is easy to adapt to and use SaaS & $0 \%$ & $0 \%$ & $11.1 \%$ & $36.1 \%$ & $52.8 \%$ & $100 \%$ \\
\hline SaaS has led to a high satisfaction rate among customers & $0 \%$ & $0 \%$ & $38.9 \%$ & $27.8 \%$ & $33.3 \%$ & $100 \%$ \\
\hline
\end{tabular}

Note: Table 1 shows distribution of responses on end user effects

\section{Functional Effects}

The respondents were asked to state the extent to which they agreed to the statements on functional effects as a result of adoption and use of SaaS. This was on a scale of 1-5, strongly disagree (1); disagree (2); neutral (3); agree (4); strongly agree (5). The key factors rated by the respondents were: difficulty of deploying SaaS, competitiveness, 
dependability and SaaS ability to assist in solving business objectives. All the 35 respondents from the 35 SMEs filled the questionnaire appropriately. The findings are presented in the Table 2.

Table 2. Respondents functional effects of using SaaS

\begin{tabular}{|c|c|c|c|c|c|c|}
\hline & $\begin{array}{l}\text { Strongly } \\
\text { Disagree }\end{array}$ & Disagree & Neutral & Agree & $\begin{array}{c}\text { Strongly } \\
\text { Agree }\end{array}$ & Total \\
\hline Customizing SaaS to fit business needs was simple & $2.8 \%$ & $8.3 \%$ & $27.8 \%$ & $33.3 \%$ & $27.8 \%$ & $100 \%$ \\
\hline SaaS enables me to finish task faster and efficiently & $0 \%$ & $0 \%$ & $11.1 \%$ & $44.4 \%$ & $44.4 \%$ & $100 \%$ \\
\hline SaaS is always available when I need to use it & $2.8 \%$ & $2.8 \%$ & $13.9 \%$ & $44.4 \%$ & $36.1 \%$ & $100 \%$ \\
\hline Using SaaS has enabled the organization achieve its set objectives & $0 \%$ & $2.8 \%$ & $22.2 \%$ & $50 \%$ & $25 \%$ & $100 \%$ \\
\hline
\end{tabular}

Note: Table 2 shows distribution of responses on functional effects

\section{Economic Effects}

The respondents were asked to state the extent to which they agreed to the statements on economic effects as a result of adoption and use of SaaS. This was on a scale of 1-5, strongly disagree (1); disagree (2); neutral (3); agree (4); strongly agree (5). The key factors rated by the respondents were: increase in revenue, reduce required upfront investments, reduce maintenance cost and increase in acquiring targeted customers. All the 35 respondents from the 35 SMEs filled the questionnaire appropriately. The findings are presented in the Table 3.

Table 3. Respondents Economic Effects of using SaaS

\begin{tabular}{|c|c|c|c|c|c|c|}
\hline & $\begin{array}{l}\text { Strongly } \\
\text { Disagree }\end{array}$ & Disagree & Neutral & Agree & $\begin{array}{l}\text { Strongly } \\
\text { Agree }\end{array}$ & Total \\
\hline SaaS use has led to increase in income generation in the organization & $0 \%$ & $2.8 \%$ & $41.7 \%$ & $38.9 \%$ & $16.7 \%$ & $100 \%$ \\
\hline SaaS use reduced required up-front investments & $2.8 \%$ & $2.8 \%$ & $22.2 \%$ & $50 \%$ & $22.2 \%$ & $100 \%$ \\
\hline SaaS use has reduce running and maintenance costs & $0 \%$ & $8.3 \%$ & $8.3 \%$ & $58.3 \%$ & $25.0 \%$ & $100 \%$ \\
\hline SaaS used has enabled capture of targeted market/customers & $0 \%$ & $0 \%$ & $22.2 \%$ & $50 \%$ & $27.8 \%$ & $100 \%$ \\
\hline
\end{tabular}

Note: Table 3 shows distribution of responses on economic effects

\section{DISCUSSION OF CONCLUSIONS AND RECOMMENDATIONS}

\section{Discussion}

\section{User Effect}

The key factors rated by the respondents in the effect of SaaS on end user were: Teleworking, reduction in number of IT staff, reduced training needs, ease of use and increased customer satisfaction. Teleworking received the highest positive percentage by the respondent which was in line with a study done in Germany where the ability to access SaaS from any location were a big factor for them using SaaS (Haselmann, 2011).

Figure 1 shows the general response type for end user effects. $72 \%$ of all the responses from the key factors were positive (agree and strongly agree) while $4 \%$ were negative and $24 \%$ were neutral. This shows that generally SaaS improves the economic aspect of an SME.

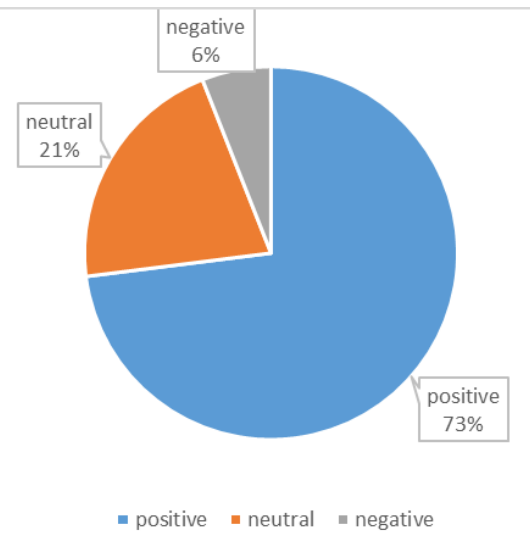

Figure 1. Combined End user effects response type for all key factors

Ease of use and adaption to $\mathrm{SaaS}$ also received a very high positive percentage which was in line with the results derived from a study done in Turkey on SMEs SaaS use which cited ease of use of the SaaS applications as a key driver to adoption of use (Salih, 2012). Reduction in number of IT staff attained an average positive response showing that use of SaaS does not eliminate the need of hiring IT professionals by the SMEs. Again this result was 
in line with past studies that had been done (Salih, 2012). The highest negative response in this category was that use of SaaS does not require any training which had a combined percentage of $19 \%$ (disagree and strongly disagree). This was understandable because any new software requires some training to get the users up and running. The other indicators recorded very low negative responses thus showing that SaaS use leads to a positive effect on the end user.

\section{Functional Effect}

The key factors rated by the respondents were: difficulty of deploying SaaS, competitiveness, dependability and SaaS ability to assist in solving business objectives. Dependability of SaaS which tested if SaaS was always available when they needed to use it, competitiveness which tested if SaaS use led to the SMEs finishing their tasks faster and SaaS ability to assist in solving business objectives efficiently received very high positive percentages. This was in line with past studies that show that use of technology enhances the business processes and makes it more efficient (Mpho, 2013). Customizing SaaS to fit business needs received the highest negative percentage which could be because past studies show that integration of SaaS to existing systems was recorded as a hindrance to SMEs adopting SaaS in Turkey (Salih, 2012). In general the recorded positive percentage greatly outweighed the negative percentage which showed that SaaS use has a positive impact on SMEs functional effects.

Figure 2 shows the general response type for functional effects. $76 \%$ of all the responses from the key factors were positive (agree and strongly agree) while 5\% were negative and 19\% were neutral. This shows that generally SaaS improves the functional aspect SMEs.

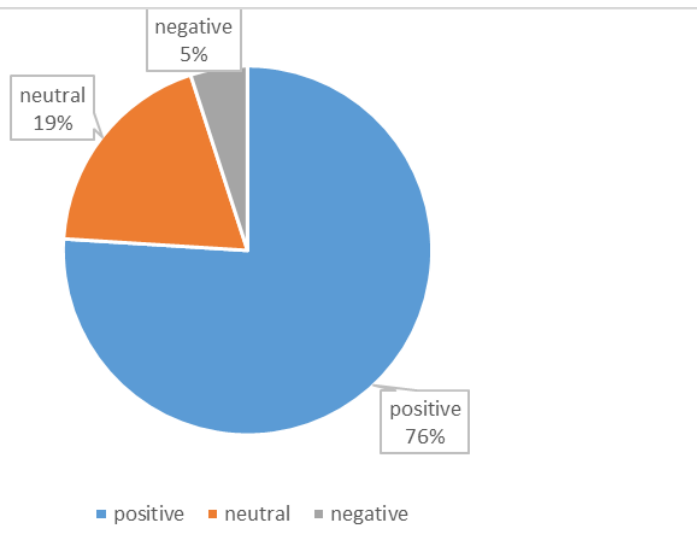

Figure 2. Combined functional effects response type for all key factors

\section{Economic Effect}

The key factors rated by the respondents were: increase in revenue, reduce required upfront investments, reduce maintenance cost and increase in acquiring targeted customers. All the factors here recorded a very high positive percentage except increase in revenue which was testing that use of SaaS leads to SMEs increasing the income they generate.

Figure 3 shows the general response type for economic effects. $72 \%$ of all the responses from the key factors were positive (agree and strongly agree) while $4 \%$ were negative and $24 \%$ were neutral. This shows that generally SaaS improves the economic aspect of an SME.

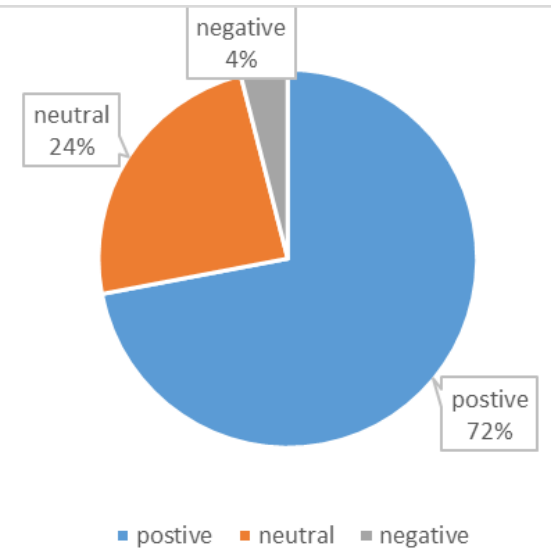

Figure 3. Combined Economic effects response type for all key 
This shows that although SaaS use may reduce running costs and reduce maintenance costs it may not play an integral part in increasing its revenue. The high positive responses in Reduce running and reduce maintenance cost were in line with studied done on SMEs SaaS use in South Africa (Mpho, 2013). This shows that the use of SaaS can lead to reduced upfront investments which means reduced capital costs thus affecting the SMEs positively.

\section{Conclusion}

From the analysis done from the gathered data in the study, the researcher found out that SaaS had positive end user effects, functional effects and economic effects on SMEs. This was shown by the low percentage of negative responses from the SMEs that were studied. The high positive percentages recorded from the end user, functional and economic effects show that SaaS use actually improves the SMEs performance. This would contribute in helping to solve the sustainability issue that SMEs in Nairobi County Kenya face.

\section{Limitations of the Study}

The major constraint in this study was the identification of SMEs that are using SaaS. This was difficult because SaaS providers sign a confidentiality agreement with their clients thus would not agree to provide the SMEs that they serve for collection of data. This was minimised by identifying some SMEs that use SaaS and then requesting them to refer to other SMEs that use the same SaaS or served by the same SaaS provider.

The other limitation was the population of the experimental group. This is because there was no official documentation of the number of SMEs using SaaS.

\section{Recommendations}

This study recommends that SMEs in Nairobi County should be encouraged to use SaaS. The study has shown that using SaaS is advantageous to SMEs as it is readily available to them at a cheaper rate and will enable to them to improve their performance which will finally enable them to have a longer sustainability. This will in turn enable the SMEs to contribute more to the GDP of the country, Kenya.

\section{Areas of Further Research}

Since this study was not based on a case study, it would be good if one SME in the county that uses SaaS would be closely studied where the daily processes of using SaaS would be recorded. Also from this study a detailed before and after scenario of using SaaS would also be recorded. Also an application performance test of SMEs using SaaS can be done in order to find out the performance experienced by end users using a SaaS application e.g. average response times under peak load, load and response times. The results of this could be useful in order to understand the appropriate internet connectivity bundle the SMEs would need for optimum performance.

\section{REFERENCES}

Abubakar, D., Julian, M. and Ian, A. (2014). Cloud computing: adoption issues for sub-Saharan African SMEs. Carole, L. and Almut, G. (2008). Validity and reliability of measurement instruments used in research.

Drost, E. (2011). Validity and Reliability in Social Science Research. Education Research and Perspectives, 38, 105-124. Garikai, B. (2011). Exportation Challenges by Small and Medium Enterprises and Possible Exportation Strategies. Given, L. M. (2008). The Sage encyclopedia of qualitative research methods. Los Angeles, Calif. Sage Publications. ISBN 14129-4163-6. https://doi.org/10.4135/9781412963909

Haselmann, T. and Vossen, G. (2011). Software-as-a-Service in Small and Medium Enterprises: An Empirical Attitude Assessment. In: Bouguettaya A., Hauswirth M., Liu L. (eds) Web Information System Engineering - WISE 2011. WISE 2011. Lecture Notes in Computer Science, vol 6997. Springer, Berlin, Heidelberg. https://doi.org/10.1007/978-3-642-24434-6_4

ILO. (1972). Employment, incomes and equity: a strategy of increasing productive employment in Kenya. Geneva: International Labour Organization.

Kenya National Bureau of Statistics. (2007). Statistical Abstract. Printed by Government Printer, Nairobi.

Kombo, D. K. and Tromp, D. L. (2006). Proposal and Thesis Writing. Makuyu: Don Bosco Printing Press.

Kunz, W. M. (2006). Culture Conglomerates: Consolidation in the Motion Picture and Television Industries. Publisher: Rowman \& Littlefield Publishers, Inc. p. 2. ISBN 0742540669.

Migir, S. (2006). Diffusion of ICTs and E-commerce adoption in manufacturing SMEs in Kenya. South African Journal of Libraries \& Information Science, 72(1), 35-44.

Mikael, J. and Daniel, P. (2015). Organizational Effects of Using SaaS Systems in SMEs. Department of Management and Engineering Economic Information Systems. Linkongpins University, Sweden. Department of Management and Engineering Economic Information Systems. 
Mohammad, Z. (2013). Mixed Method Research: Instruments, Validity, Reliability and Reporting Findings. Theory and Practice in Language Studies, 3(2), 254-262.

Moyi, E. and Njiraini, P. (2005). Misallocation of Workspaces for SMEs in Kenya: Some Lessons and Models. International Journal of Business and Economics Research, 2(3), 69-76. https://doi.org/10.11648/j.ijber.20130203.14

Mpho, J. and Nkqubela, L. (2013). The Potential of Cloud Computing as an Alternative Technology for SMEs in South Africa. International Journal of Economics, Commerce and Management, United Kingdom. II(11), Nov 2014.

Ngui, K. (2014). The Role of SMEs in Employment Creation and Economic Growth in Selected Countries. International Journal of Research and Education.

Palys, T. (2008). Purposive sampling. The Sage Encyclopedia of Qualitative Research Methods. (Vol.2).Sage: Los Angeles, pp. 697-8.

Peppard, J. (1993). IT Strategy for Business. Pitman Publishing, London.

Salih, B. (2012). Analysis of SaaS and On Premise ICT solutions for SMEs in Turkey. Available at: http:/ / docplayer.net/4135590-Analysis-of-saas-and-on-premise-ict-solutions-for-smes-in-turkey.html (Retrieved 31 January 2018)

Sanchita, C. (2013). A Study of Issues \& Challenges of Implementation of Information Technology in HRM. Research India Publications.

Satyanarayana, S. (2011). Cloud Computing SaaS. GESJ: Computer Science and Telecommunications 2012|No.4 (36) ISSN 1512-1232

Singh, A. and Masuku, B. (2014). Sampling techniques \& determination of sample size in applied statistics research: an overview. International journal of economics, commerce and management. United Kingdom II(11), Nov 2014.

Tilman, A. and Ute, E. (2006). Productivity enhancement and equitable development: Challenges for SME development. United Nations Industrial Development Organization, Vienna,

Vogt, W. (1999). Dictionary of Statistics and Methodology: A Nontechnical Guide for the Social Sciences, London: Sage.

Wohl, A. (2008). Succeeding at SaaS: Computing in the cloud. Published by Wohl Associates.

Wu, J., Ping, L. and Pan X. (2009). Cloud Computing: Concept and Platform, Telecommunications Science.

\section{APPENDICES}

\section{Appendix 1: Questionnaire}

Questionnaire Code:

Date:

Survey: Effects of SaaS on SMEs

Introduction

This questionnaire is part of a study on the use and effect of SaaS by SMEs companies in Nairobi County. Your participation in this study is voluntary. The questions will purely be used to satisfy an academic requirement only, and not for any statistical study. We will not identify you as an individual. The researcher would be most grateful if you give your views by answering the questions below. Be assured that Confidentiality of Information solicited is guaranteed.

Thank you

\section{SECTION A}

Instructions: Please tick the appropriate answer

1. Do you use a SaaS application in your organization? (If answer is no please do not fill the rest of the questionnaire)

Yes $\square \quad$ No

2. Are you male or female?

Male $\square \quad$ Female

3. For how long have you used SaaS in your organization?

a) 3 months

b) 6months

c) 1 year

d) More than one year 


\section{SECTION B}

Instructions: Please tick the benefits that you have felt that your company has generally enjoyed by using SaaS.

(You are allowed to tick more than one answer)
a) Low cost of entry
b) Pay as you go
c) Easy to scale
d) Work anywhere/accessibility
e) Seamless upgrades/ integration
f) Affordable
g) Zero/less Infrastructure
h) Easy to switch vendors
i) Full configurability
j) Inclusive backup/disaster recovery

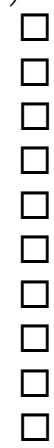

Please list any other benefit that your company enjoyed through use of SaaS and it is not listed above:

\section{SECTION C}

Instructions: Please indicate your level of agreement or disagreement with each of these statements regarding the effect that SaaS has on your company. Place an "X" mark in the box of your answer.

\begin{tabular}{|c|c|c|c|c|c|c|}
\hline A. & End user Effects & & & & & \\
\hline & & $\begin{array}{c}1 \\
\text { Strongly } \\
\text { Disagree }\end{array}$ & $\begin{array}{c}2 \\
\text { Disagree }\end{array}$ & $\begin{array}{c}3 \\
\text { Neutral }\end{array}$ & $\begin{array}{c}4 \\
\text { Agree }\end{array}$ & $\begin{array}{c}5 \\
\text { Strongly } \\
\text { Agree }\end{array}$ \\
\hline a) & Use of SaaS enables me to work away from the office frequently & & & & & \\
\hline b) & SaaS has led to a reduced number of IT staff & & & & & \\
\hline c) & Use of SaaS does not need any training & & & & & \\
\hline d) & It is easy to use and adapt to SaaS & & & & & \\
\hline e) & SaaS has led to a high satisfaction rate among customers & & & & & \\
\hline \multirow[t]{2}{*}{ B. } & Functional Effects & & & & & \\
\hline & & $\begin{array}{c}1 \\
\text { Strongly } \\
\text { Disagree }\end{array}$ & $\begin{array}{c}2 \\
\text { Disagree }\end{array}$ & $\begin{array}{c}3 \\
\text { Neutral }\end{array}$ & $\begin{array}{c}4 \\
\text { Agree }\end{array}$ & $\begin{array}{c}5 \\
\text { Strongly } \\
\text { Agree }\end{array}$ \\
\hline a) & Customizing SaaS to fit business needs was simple & & & & & \\
\hline b) & SaaS enables me to finish task faster and efficiently & & & & & \\
\hline c) & SaaS is always available when I need to use it & & & & & \\
\hline d) & Using SaaS has enabled the organization achieve its set objectives & & & & & \\
\hline \multirow[t]{2}{*}{ C. } & Economic Effects & & & & & \\
\hline & & $\begin{array}{c}1 \\
\text { Strongly } \\
\text { Disagree }\end{array}$ & $\begin{array}{c}2 \\
\text { Disagree }\end{array}$ & $\begin{array}{c}3 \\
\text { Neutral }\end{array}$ & $\begin{array}{c}4 \\
\text { Agree }\end{array}$ & $\begin{array}{c}5 \\
\text { Strongly } \\
\text { Agree }\end{array}$ \\
\hline a) & SaaS use has led to increase in income generation in the organization & & & & & \\
\hline b) & SaaS use reduced required up-front investments & & & & & \\
\hline c) & SaaS use has reduce running and maintenance costs & & & & & \\
\hline d) & SaaS used has enabled capture of targeted market/customers & & & & & \\
\hline
\end{tabular}

Thank You!!! 


\section{Appendix 2: SMEs Studied}

1. Institute of Software Technologies

2. Software Technology Ltd

3. Africa Blue Webs

4. KEMIS hub

5. Pay kind Ltd

6. M: Lab East Africa

7. Codverse Technology

8. Novum Technologies

9. Syslog Solutions

10. Bio Medica Laboratories

11. Greenworld Initiative

12. Nixtech communications services Ltd

13. Arifu Ltd

14. Smart Hand Solutions

15. Arithentic Services

16. Ntabo Photography

17. Dynamic Systems

18. Telemas Company Limited

19. Safari Trails Limited

20. BuyMore POS

21. Techno Sol

22. Villgro Kenya

23. Quavatel Limited

24. Eldohub Innovation Centre

25. Olanic Oak Kenya Ltd

26. Chadh Events Ltd

27. Vittorio Dry Cleaners

28. Motogari

29. Tech starlets

30. Zalika Creatives

31. Ahadi Express Services

32. Dessin Impression

33. Golden Height Complex

34. Kethem Data Solution

35. Al Husain motors ltd 